\title{
CHARACTERIZATION OF THE COAL HUMIC ACIDS FROM THE CANDIOTA COALFIELD, BRAZIL
}

\author{
XAVIER D.M. ${ }^{1}$, SILVA A.S. ${ }^{1}$, SANTOS R.P. ${ }^{2}$, MESKO M.F. ${ }^{1}$, COSTA S.N. ${ }^{3}$, FREIRE V.N. ${ }^{3}$, CAVADA B.S. ${ }^{4}$ AND \\ MARTINS J.L. ${ }^{1 *}$
}

1Departamento de Química Analítica e Inorgânica, Universidade Federal de Pelotas, Pelotas, Rio Grande do Sul, Brazil. 2Laboratório de Engenharia de Materiais e da Computação de Sobral (LEMCS), Universidade Federal do Ceará, Sobral, Ceará, Brazil. 32Departamento de Física, Universidade Federal do Ceará, Fortaleza, Ceará, Brazil. ${ }^{4}$ Laboratório de Moléculas Biologicamente Ativas, Departamento de Bioquímica, Universidade Federal do Ceará, Fortaleza, Ceará, Brazil. *Corresponding Author: Email-jmartins.martins@gmail.com

Received: May 11, 2012; Accepted: June 25, 2012

\begin{abstract}
Humic acid $(\mathrm{HA})$ is a principal component of humic substances, which are the major organic constituents of soil, peat, coal, many upland streams, dystrophic lakes and ocean water. HA has an important impact on a variety of environment processes. This work aimed to characterize the HA extracted and purified from the Candiota coalfield (Brazil) by visible (VIS), Fourier transform infrared (FTIR), energy dispersive X-ray (EDX), inductively coupled plasma absorption emission (ICP-AES), and X-ray diffraction (XRD) spectroscopies, thermogravimetry (TG), differential thermal analysis (DTA), and scanning electron microscopy (SEM). The results of these analyses showed that Candiota HA presents a high degree of humification, which is considered to be type A with a turbostratic structure. The elemental analysis (EDX/ ICP-AES) indicated the presence of low concentrations of heavy metals.
\end{abstract}

Key words - Humic acid, coal, characterization, spectroscopy, thermal analyses.

Citation: Xavier D.M., et al. (2012) Characterization of the Coal Humic Acids from the Candiota Coalfield, Brazil. International Journal of Agriculture Sciences, ISSN: 0975-3710 \& E-ISSN: 0975-9107, Volume 4, Issue 5, pp-238-242.

Copyright: Copyright@2012 Xavier D.M., et al. This is an open-access article distributed under the terms of the Creative Commons Attribution License, which permits unrestricted use, distribution, and reproduction in any medium, provided the original author and source are credited.

\section{Introduction}

The organic matter of soils can be divided into non-humic and humic substances. Carbohydrates, amino acids, protein, lipids, nucleic acids, and lignins are non-humic substances that originate from plants and other organisms. However, humic substances (HSs) are materials synthesized during the decomposition of plants and animal residues with or without the assistance of microorganisms (humification). HSs are defined as hydrophilic, acidic, high molecular weight, amorphous, and colloidal polydispersed substances with a yellow to brown-black color [1]. HSs are not only found in soils, but are also distributed among several environments, such as streams, rivers, lakes, oceans, sediments, and geologic deposits [2,3,4]. HSs are major importers, exporters and transporters of solutes in soils and natural waters, and they play a much greater role than clays and minerals in this respect [5].

Based on their solubility properties, HSs are generally classified into the three following categories: humic acids (HAs), fulvic acids, and humin [6]. These three humic fractions are structurally similar and their properties differ, especially with respect to their molecular weight, their ultimate analysis, and the number of functional groups present [7]. The predominant fractions of humic substances are HAs [8]. HAs are defined as organic macromolecules with high molecular mass, larger carbon contents, and smaller oxygen contents due to their phenol and carboxylic groups and are soluble at alkaline pH values [4]. HAs have an important role in soil fertility and to bind many heavy metallic ions through complexation $[4,9,10]$. HAs are present in larger amounts in terrestrial and geologic humic matter and in smaller amounts in aquatic humic matter [1].

The mineral coal, which results from the accumulation of the remains of organic material, contains HSs in its composition. The coal organic matter contains significant amounts of oxygen, nitrogen and sulfur. HSs also contain those elements in their composition in the form of functional groups such as carboxylic acid, ketones, and amines [11]. The most important mineral coalfield in Brazil is the Candiota coalfield, which is located in the Rio Grande 
do Sul state. Candiota contributes $37.9 \%$ of the national mineral coal because the Candiota field is the largest deposit of mineral coal in Latin America [12].

The characteristics of HAs are associated with their origin [13]. The physiochemical characterization of the HAs is indispensable $[4,9,10]$. Several methods (destructive and non-destructive) are used for the characterization of HAs. Different techniques supply important information for understanding the structure, composition and properties of these materials [14]. Fourier transform infrared (FTIR), ultraviolet-visible (UV-VIS), inductively coupled plasma absorption emission (ICP-AES) and solid-state ${ }^{13} \mathrm{C}$ nuclear magnetic resonance (CP-MAS 13C NMR) spectroscopies; X-ray diffraction (XRD); scanning electron microscopy (SEM); thermogravimetry (TG); and differential thermal analysis (DTA) are some of the commonly techniques used for the characterization of HAs $[15,16]$.

The purpose of this study is to characterize humic acids extracted from mineral coal from the Candiota coalfield (Rio Grande do Sul state, Brazil) using visible (VIS) absorbance, Fourier transform infrared (FTIR), energy dispersive X-ray (EDX), inductively coupled plasma absorption emission (ICP-AES), and X-ray diffraction (XRD) spectroscopies, thermogravimetry (TG); differential thermal analysis (DTA); and scanning electron microscopy (SEM).

\section{Materials and Methods}

In this study, samples of mineral coal from the Candiota coalfield (Rio Grande do Sul State, Brazil) were collected directly from the mine in August of 2009. The samples were air-dried, ground, and sieved through a 1-mm sieve. Humic acid $(\mathrm{HA})$ was isolated from the samples using conventional methods [4]. In brief, humic substances were extracted using $1.0 \mathrm{M} \mathrm{NaOH}$. The extracted humic substances were then separated into $\mathrm{HA}$ and fulvic acid (FA) fractions by acidifying the extract to $\mathrm{pH} 1-1.5$ using $6.0 \mathrm{M} \mathrm{HCl}$. The extracted $\mathrm{HA}$ was purified according to the procedure reported by Stevenson [4]. The HA fraction was suspended in a solution of 0.1 $\mathrm{M} \mathrm{HCl}$ and $0.3 \mathrm{M} \mathrm{HF}$ to remove mineral impurities and then dialyzed until $\mathrm{Cl}^{-}$was eliminated. The purified $\mathrm{HA}$ from the mineral coal from the Candiota coalfield (CHA) was freeze-dried for chemical analysis.

For absorbance measurements, the $\mathrm{CHA}$ samples $(1 \mathrm{mg})$ were dissolved in $100 \mathrm{~mL}$ of $0.1 \mathrm{M} \mathrm{NaOH}$, and the absorbance (Abs) was measured at 400, 465, 600 and $665 \mathrm{~nm}$ with a J\&M TIDASDAQ spectrometer. The results (mean value of ten repetitions) were used to calculate the $E_{4} / E_{6}$ ratio $\left(A b s_{465} / A b s_{665}\right)$ and $\Delta$ Log $K$ coefficient (Log Abs400-Log Abs600) according to Giovanela [16]. These parameters are widely used for the characterization of humic substances.

The Fourier transform infrared (FTIR) spectra were recorded in the transmission mode by a Shimadzu IR Prestige-21 spectrophotometer using a $\mathrm{KBr}$ pellet containing $1 \% \mathrm{CHA}$. The infrared spectra were recorded at $4 \mathrm{~cm}^{-1}$ resolution from $5000 \mathrm{~cm}^{-1}$ to $450 \mathrm{~cm}^{-1}$. The spectra were automatically corrected for the $\mathrm{KBr}$ background to minimize the $\mathrm{CO}_{2}$ and $\mathrm{H}_{2} \mathrm{O}$ absorptions.

The thermal analyses (TGA and DTA) were performed in a nitrogen atmosphere, with a $10^{\circ} \mathrm{C} / \mathrm{min}$ heating ratio, from $23.8^{\circ} \mathrm{C}$ to $1000^{\circ} \mathrm{C}$, using Shimadzu DTG 60 equipment.

The elemental composition of the CHA was determined by an energy dispersive X-ray analysis (EDX) and inductively coupled plasma atomic emission spectrometry (ICP-AES). Qualitative measurements were performed using a Shimadzu Ray Ny-EDX 720. The concentrations of $\mathrm{Al}, \mathrm{Ca}, \mathrm{Cd}, \mathrm{Co}, \mathrm{Cu}, \mathrm{Fe}, \mathrm{K}, \mathrm{Mg}, \mathrm{Mn}, \mathrm{Mo}$, $\mathrm{Na}, \mathrm{Ni}, \mathrm{Pb}, \mathrm{V}, \mathrm{Zn}$, and $\mathrm{Sr}$ were determined (mean value of three repetitions) by ICP-AES with a Perkin-Elmer ICP-AES instrument, model Optima 4300DV, after digestion (humid) in the microwave with a closed system using concentrated $\mathrm{HNO}_{3}$.

The X-ray diffraction (XRD) patterns for the mineralogical analyses were obtained at room temperature $(300 \mathrm{~K})$ using a Shimadzu XRD-6000 powder diffractometer. A Bragg-Bretano geometry was used with $\mathrm{Cu}$-ka radiation. The tube was operated at $40 \mathrm{kV}$ and $40 \mathrm{~mA}$. The diffraction data were collected over the range of $10^{\circ} \leq 2 \theta \leq 80^{\circ}$ with $0.02^{\circ}$ steps and an integration time of $2 \mathrm{~s}$ per point.

The SEM micrographs of the CHA powder were obtained with a Shimadzu SSX-550 scanning electron microscope. The freezedried samples were previously coated with a thin gold layer in a Quick Coater SC-701 sputtering system for 10 min before analysis.

\section{Results and Discussion}

The values of the $E_{4} / E_{6}$ ratio and the $D \log K$ coefficient for the $\mathrm{CHA}$ were $3.20 \pm 0.10$ and $0.42 \pm 0.02$, respectively, which are considered to be type $A$ ( $D \log K<0.6$ - high degree of humification), according to Kumada [14]. These results suggest that the HA-C presents a high structural condensation (larger amount of aromatic structures than aliphatic structures) and a large molecular size [17]. The measured $E_{4} / E_{6}$ and $D \log K$ values are among the smallest values reported $[4,16,18]$.

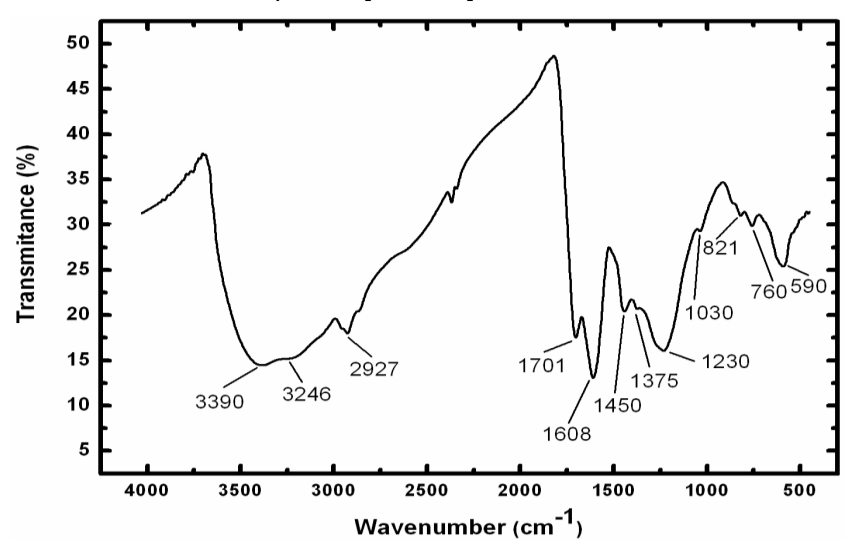

Fig. 1- FTIR spectra of the CHA showing the principal absorption bands.

Fig. 1 shows the FTIR spectrum for the CHA. The broad bands detected in the $3680-3000 \mathrm{~cm}^{-1}$ region were attributed to the $\mathrm{O}-\mathrm{H}$ stretching of alcohols and/or phenols, as well as $\mathrm{N}-\mathrm{H}$ stretching of amines and/or amides [19]. The bands between 3000 and 2855 $\mathrm{cm}^{-1}$ correspond to the asymmetric and symmetric $\mathrm{C}-\mathrm{H}$ stretching of methyl and methylene groups of aliphatic and nonstrained cyclic hydrocarbons [16]. This region shows the degree of saturation of the sample, revealing a low percentage of aliphatic carbons in the CHA. The sharp band at $1701 \mathrm{~cm}^{-1}$ was attributed to the $\mathrm{C}=0$ stretching vibrations due to carboxylic groups [20]. The strong band detected at $1608 \mathrm{~cm}^{-1}$ indicated the presence of aromatic ring $\mathrm{C}=\mathrm{C}$ stretching [21]. Absorption at $1450 \mathrm{~cm}^{-1}$ was due to ali- 
phatic $\mathrm{C}-\mathrm{H}$ deformation [8]. The absorption band attributed to the $\mathrm{C}-\mathrm{H}$ bending of $\mathrm{CH}_{3}$ and $\mathrm{C}-\mathrm{H}$ deformation of $\mathrm{CH}_{2}$ and $\mathrm{CH}_{3}$ groups was measured at $1375 \mathrm{~cm}^{-1}[16]$. The bands at 1230 and $1030 \mathrm{~cm}$ ${ }^{-1}$ corresponded, respectively, to the aromatic ether C-O-C and C0 stretching of polysaccharide $[19,22]$. Absorption bands attributed to the aromatic $\mathrm{C}$ - $\mathrm{H}$ out-of-plane deformation of aromatic structures were observed in the $860-720 \mathrm{~cm}^{-1}$ region [23]. The Si-O stretching absorption occurred at $590 \mathrm{~cm}^{-1}[24]$. This band may represent silicate impurities [25]. The bands observed in the FTIR showed that the $\mathrm{CHA}$ is rich in aromatic structures, according to results from VIS spectroscopy.

The thermal analyses (Fig. 2) indicated the occurrence of three events: the first, between 28 and $140{ }^{\circ} \mathrm{C}$, corresponded to a $7.7 \%$ mass loss; the second, between 140 and $360^{\circ} \mathrm{C}$, corresponded to an $8.8 \%$ mass loss; and the third, between 360 and $535{ }^{\circ} \mathrm{C}$ (exothermic DTA peak at $450.7^{\circ} \mathrm{C}$ ), corresponded to a $75 \%$ mass loss. The first two events were identified only in TG. The last was identified in TG as well as in DTA. The first event was attributed to the loss of free water (dehydration) from the CHA sample [26]. The second event was associated with the degradation of polysaccharides, the decarboxylation of acidic groups and the dehydration of aliphatic alcohols [27]. The third event (which showed a larger mass loss) was attributed to the decomposition of aromatic structures and cleavage of $\mathrm{C}-\mathrm{C}$ bonds [28]. Consequently, the strong exothermic peak at approximately $450^{\circ} \mathrm{C}$ showed a larger number of aromatic structures relative to the aliphatic structures in the CHA (high degree of humification). This characteristic has been observed in HAs extracted from coals [29].

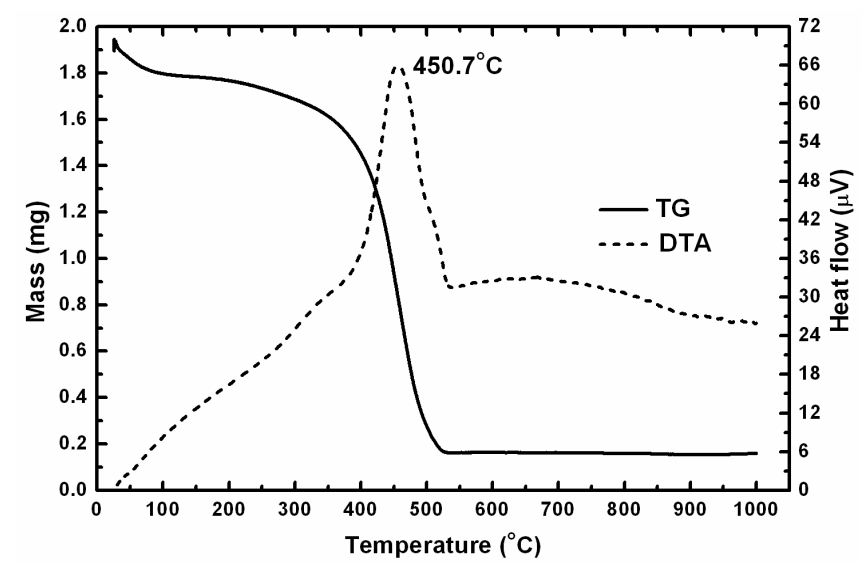

Fig. 2- TG and DTA curves for the CHA. The value indicated represents an exothermic peak

With respect to the elemental composition of the CHA, EDX qualitative measurements indicated the presence of $\mathrm{Br}, \mathrm{S}, \mathrm{Rh}, \mathrm{Ba}, \mathrm{Ti}$, $\mathrm{Fe}, \mathrm{Ni}, \mathrm{Mo}, \mathrm{Na}, \mathrm{Al}, \mathrm{Si}, \mathrm{Ca}, \mathrm{Te}$, and $\mathrm{V}$. Other elements may be present but not detectable by EDX because of low concentrations. Table 1 shows the results of the ICP-AES analysis. ICP-AES allows for the determination of small concentrations ( $\mathrm{ppb}$ ) of metallic elements in a sample. All the elements investigated showed low concentrations. $\mathrm{Na}$ was the most prevalent element (approximately $1.05 \%$ ), followed by $\mathrm{Al}$ (approximately $0.12 \%$ ). Other elements showed concentrations below $0.03 \%$ or concentrations below the detection limit ( $\mathrm{Cd}, \mathrm{Co}$, and $\mathrm{Pb}$ ). Unpurified Has generally contain a large quantity of $\mathrm{Na}$ and $\mathrm{Ca}$, which originate from the alkaline treatment during the extraction and high rates of occurrence of $\mathrm{Si}, \mathrm{Fe}$ and $\mathrm{Al}$ in the form of impurities [30]. The low concentrations observed by ICP-AES revealed the effect of purification of the CHA. The purification process performed after the extraction causes a significant loss of cations, thereby decreasing the elemental concentration. Very few of the metallic elements detected can be incorporated into the CHA structure because of the capacity of the CHA to bind many heavy metallic ions through complexation $[31,32]$. Other elements such as $\mathrm{Si}$ can originate from impurities. $\mathrm{S}$ should be incorporated into the $\mathrm{CHA}$ structure [33].

Table 1- Result of ICP-AES measurements of HA-C. Concentrations below the detection limit are marked as "*"

\begin{tabular}{|llll|}
\hline Metal & Concentration $\left(\boldsymbol{\mu g g}^{-1}\right)$ & Metal & Concentration $\left(\right.$ ugg $\left.^{-1}\right)$ \\
$\mathrm{Al}$ & $1259 \pm 55$ & $\mathrm{Mo}$ & $60.6 \pm 2,5$ \\
$\mathrm{Ca}$ & $201 \pm 28$ & $\mathrm{Na}$ & $10552 \pm 62$ \\
$\mathrm{Cd}$ & $*$ & $\mathrm{Ni}$ & $11 \pm 2$ \\
$\mathrm{Co}$ & $*$ & $\mathrm{~Pb}$ & $*$ \\
$\mathrm{Cu}$ & $15.5 \pm 0,9$ & $\mathrm{~V}$ & $10.1 \pm 0,4$ \\
$\mathrm{Fe}$ & $137 \pm 15$ & $\mathrm{Na}$ & $4.72 \pm 0,22$ \\
$\mathrm{~K}$ & $44.8 \pm 2,0$ & $\mathrm{Sr}$ & $3.46 \pm 0,25$ \\
$\mathrm{Mg}$ & $45.4 \pm 9,0$ & $\mathrm{Mn}$ & $5.74 \pm 1,30$ \\
\hline
\end{tabular}

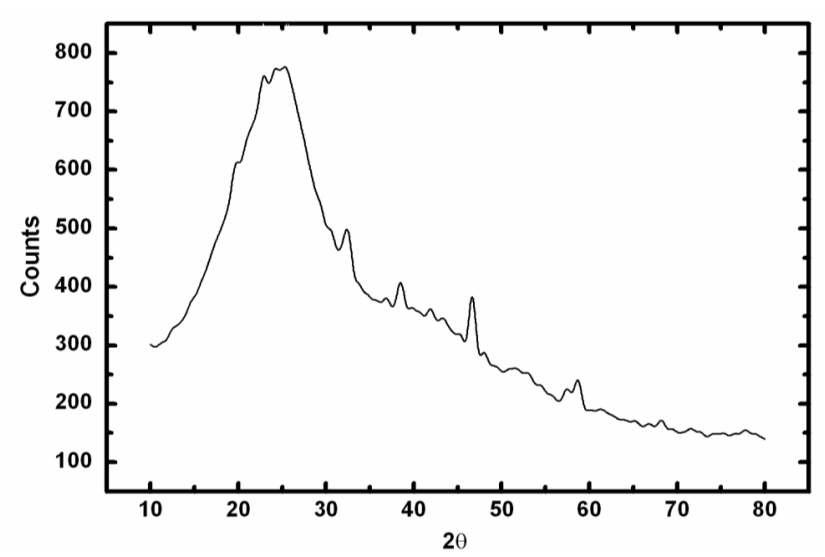

Fig. 3- XRD pattern for the CHA. Some peaks associated with crystalline phases can be observed

The X-ray diffraction pattern is shown in Fig. 3. A broad and symmetric peak was observed around at $2 q=24.80^{\circ}$, corresponding to an interplanar spacing of approximately $3.59 \AA$. A broad and feeble peak was also observed at approximately $2 q=40.40^{\circ}$, corresponding to an interplanar spacing of approximately $2.25 \AA$. These peaks were attributed to the (002)- and (01)-bands of graphite, respectively [34]. HAs with these bands contain stacked fractions of several layers with interplanar spacing between 3.4 and $3.6 \AA$ of condensed rings composed of several benzene rings (turbostratic structure) $[14,15]$. The type A HAs show this structure, which is associated with the high degree of humification this type of HAs [14]. Consequently, the CHA presumably has a turbostratic structure. The X-ray diffraction pattern of the $\mathrm{CHA}$ was similar to the pattern of Sochiken-1 HA [14]. Sharp peaks (unidentified) associated with crystalline phases were also were observed on the diffractogram. These phases (impurities) presum- 
ably are composed of the elements detected in the EDX/ICP-AES analyses. Further experiments will be performed to identify these crystalline phases.

Fig. 4 shows SEM images of the CHA particles at different magnifications. Particles with different shapes and sizes can be observed (Figs. 4a, 4b). At high magnification (Figs. 4c, 4d), the surfaces of these particles revealed a rough structure consisting of aggregates of particles smaller than $90 \mathrm{~nm}$. The presence of some porous particles with a mean size of $110 \mathrm{~nm}$ was also observed. These values were measured directly on the image at high magnification. Evidently, the values obtained are approximate because we are at the SEM resolution limit. The mechanisms involved in the molecular aggregation process can be weak, such as London and van der Waals forces, or strong, such as charge transfer and hydrogen bonding [16]. High structural condensation and large-size molecules (suggested by the characterization techniques) can favor the strong interactions between the CHA molecules. These interactions would promote the cohesion of the molecules in small particles to form larger aggregates (particles observed in low magnifications) during the drying process after purification. This hypothesis still needs to be tested.

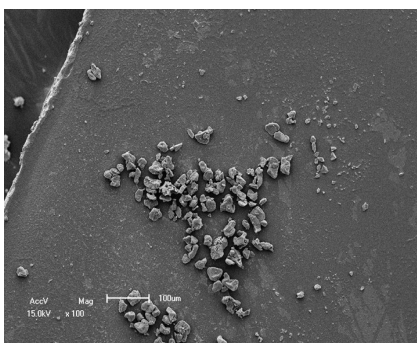

(a)

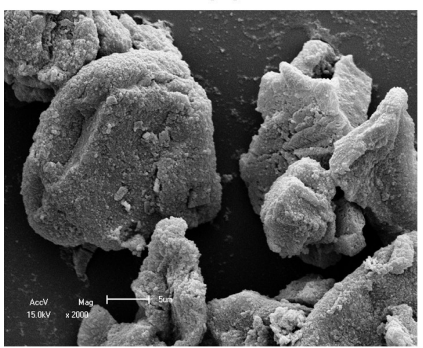

(c)

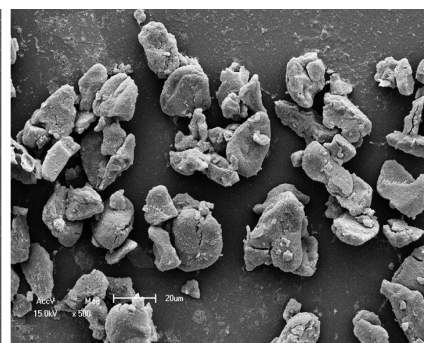

(b)

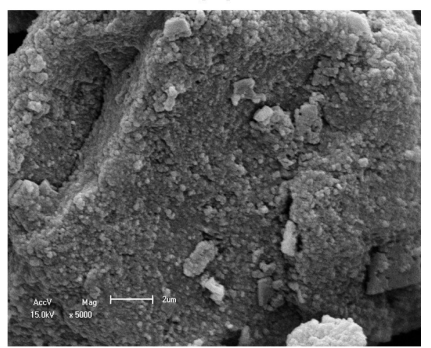

(d)
Fig. 4- SEM images of the CHA. Magnifications: (a) 100x, (b) $500 x$, (c) 2000x, and (d) 5000x. Small pores can be observed on the rough surface at high magnification

\section{Conclusions}

Characterization by absorbance $\left(E_{4} / E_{6}\right.$ ratio and $\Delta$ Log $K$ coefficient), FTIR, TG/DTA, XRD, and SEM showed that the purified humic acid from Candiota ( $\mathrm{CHA}$ ) presents a high degree of humification, which is considered to be type A with a turbostratic structure. The $E_{4} / E_{6}$ and $D \log K$ values are among the smallest values reported for humic acids, presumably indicating that the $\mathrm{CHA}$ is relatively rich in carboxylic and phenolic groups. The functional groups that contribute most to surface charge and reactivity of humic substances are phenolic and carboxylic groups. The presence of carboxylic and phenolic groups gives the humic acids the ability to form complexes [4]. Consequently, the CHA can exhibit a high capacity to complex with heavy metallic ions. The elemental analysis (EDX/ICP-AES) indicated the presence of low concentrations of heavy metals

\section{Acknowledgments}

We would like to thank the professors, technicians and students of the Biotechnology Center of Sobral (NUBIS) and Material Science and Technology (LCTM) of the Federal University of Ceará, CE, Brazil and the Environmental Chemistry Laboratory of the Federal University of Pelotas, RS, Brazil, for the research facilities, technical support and important suggestions for the elaboration of this work. Benildo Sousa Cavada (B. S. Cavada), Ricardo Pires dos Santos (R. P. Santos), and Valder Nogueira Freire (V. N. Freire) are investigators of $\mathrm{CNPq}$ (Brazil). This work received partial financial support from National Council of Research (CNPq) - projects nos. 501221/2009-3 and 473911/2010-8.

\section{References}

[1] Tan H.K. (1998) Principles of soil chemistry, 3rd ed., Marcel Dekker, New York.

[2] Schnitzer M. (1978) Soil Sci., 8, 1-64.

[3] Hayes M.H.B. and Clapp C.E. (2001) Soil Sci., 166, 723-737.

[4] Stevenson F.J. (1994) Humus Chemistry, Genesis, composition, reactions, 2 rd ed., John Wiley \& Sons, New York.

[5] Ghabbour E.A. and Davies G. (2005) Humic substances, Nature's Most Versatile Materials, Taylor \& Francis, New York.

[6] Steinberg C.E.W. (2003) Ecology of Humic Substances in Freshwaters, New York.

[7] Pansu M. and Gautheyrou J. (2006) Handbook of soil analysis, New York.

[8] Mengchang H., Yehong S. and Chunye L. (2008) J. Environ. Sci., 20, 1294-1299.

[9] Vaughan D. and Malcolm R.E. (1985) Influence of humic substances on growth and physiological processes. In: Soil Organic Matter and Biological Activity.

[10]Da Silva R.M., Jablonski A., Siewerdt L. and Silveira P. (2000) R. Bras. Zootec., 29, 1623-1631.

[11]Lawson G.J. and Stewart D. (1989) Coal Humic Acids. In: Humic Substances II. In Search of Structure.

[12]Departamento Nacional de Produção Mineral (1996) Informativo Anual da Indústria Carbonífera. Ministério de Minas e Energia, Brasilia.

[13]Olivella M.A., del Rio J.C., Palácios J., Vairavamurthy M.A. and las Heras F.X.C. (2002) J. Anal. Appl. Pyrolysis, 63, 5968.

[14]Kumada K. (1987) Chemistry of Soil Organic Matter, Tokyo.

[15]Agarwal S.P., Awer M.D.K., Khanna R., Ali A., Sultana Y. and Serb J. (2010) Chem. Soc., 75, 413-422.

[16]Giovanela M., Crespo J.S., Antunes M., Adamatti D.S., Fernandes A.N., Barison A., da Silva C.W.P., Guégan R., Motelica-Heino M. and Sierra M.M.D. (2010) J. Mol. Struct., 981, 111-119.

[17]Sanches S.M., Campos S.X. and Vieira E.M. (2007) Eclet. Quím., 32, 49-56.

[18]Shirshova L.T., Ghabbour E.A. and Davies G. (2006) Geoderma, 133, 204-216.

[19]Amira S., Jouraiphyb A., Meddichb A., Gharousb M., Wintertonc P. and Hafidid M. (2010) J. Hazard. Mater., 177, 524-529. 
[20]Erdogan S., Baysal A., Akba O. and Hamamci C. (2007) Polish. J. Environ. Stud., 16, 671-675.

[21]Siddiqui Y., Meon S., Ismail R., Rahmani M. and Ali A. (2009) Int. J. Agric. Biol., 11, 448-452.

[22]Çimen F., Sozudogru S., Kayran C., Demirci S., Ozenc D.B. and Ozenc N. (2007) Biodegradation, 18, 295-301.

[23]Senesi N., Meano Y.M. and Matin J.P. (1987) Biol. Fertil. Soils, 5, 120-125.

[24]Jayaganesh S. and Senthurpandian V.K. (2010) Asian J. Earth Sci., 3, 130-135.

[25]Xu D., Zhu S., Chen H. and Li F. (2006) Colloids Surf. A, 276, 1-7.

[26]Francioso O., Ciavatta C., Montecchio D., Tugnoli V., Sanchez-Cortes S. and Gessa C. (2003) Bioresour. Technol., 88, 189-195.

[27]Fernández J.M., Hockaday W.C., Plaza C., Pólo A. and Hatcher P.G. (2008) Chemosphere, 73, 1838-1844.

[28]Francioso O., Montecchio D., Gioacchini P., Cavani L., Ciavatta C. and Trubestskoj O. (2009) Geoderma, 152, 264268.

[29]Fernandes A.N. (2007) Ph.D. Thesis, Universidade Federal de Santa Catarina, Florianópolis, p 149.

[30]Terkhi M.C., Taleb F., Gossart P., Semmoud A. and Addou A. (2008) J. Photochem. Photobiol. A, 198, 205-214.

[31]Courtijn E., Vandescasteele C. and Dams R. (1990) Sci. Total Environ., 90, 191-202.

[32]Pourret O., Davranche M., Gruau G. and Dia A. (2007) Chem. Geol., 243, 128-141.

[33] Simpson A.J., Kingery W.L., Hayes M.H.B., Spraul M., Humpfer E., Dvortsak P., Kerssebaum R., Godejohann M. and Hofmann M. (2002) Naturwissenschaften, 89, 84-88.

[34]Schnitzer M., Kodama H. and Ripmeester J.A. (1991) Soil Sci. Soc. Am. J., 55, 745-750. 